followed by reaction, with severe pain in the abdomen, which is tense, and very tender; skin hot ; face flushed; breathing hurried; the pulse excessively quick and ex. panded, 130, 140, or even more, in the minute; the patient lies on her back, with the legs flexed, and moves with great relnctance; secretion of milk scanty; lochia small in quantity, and sometimes entirely suspended.

If the disease has extended to the serous covering of the bowels, vomiting not only occurs at an early period of the attack, but the pulse is much smaller, and the tenderness extends over the whole abdomen, with greater oppression of the powers. Whichsoever condition may be found to exist, I have treated it in the same way, viz., by free and decisive blood-letting, followed with opium, a course of practice for which I am indebted to the late Dr. Armstrong. Half-measures in this formidable disease do no good; they exhaust the strength, without accomplishing the object desired.

When summoned to a case of this description, I place the patients in the semi-erect posture, and abstract blood in a free stream, until the pulse falters, and the features become pale. After rallying, I administer tbree grains of opium, and enjoin strict quietude: in four hours the case is again visited, and if the pain and tenderness be present, the pulse still continuing rapid and incompressible, I bleed again in the same way as before, to approaching syncope; and afterwards prescribe two grains of opium, combined with three or four of calomel. Should the second bleeding prove insufficient, and in two or three hours at most the inflammatory symptoms unsubdued, venesection must be repeated in the same decisive manner, followed by one grain of opium and five of calomel. It now and then happens that some slight traces of mischief yet remain, which readily give way to the application of leeches, warm cataplasms, and three graius of calomel, with one of opium, every fourth hour, nntil the gums become tender. But by far the greater number have succumbed to the first or second blood-letting (especially when seen within two or three hours after the chill), and upon visiting the patient you find she has slept; awole in a profuse perspiration. free, or nearly so, from pain or tenderness; pulse perhaps as low as 110, and compres. sible, when mild aperients, with dietetics, and great care in the general management, will, for the most part, complete the cure.

If the foregoing brief remarks upon a dis. ease which runs a far more rapid course than any other inflammation, ex cept laryngitis, on account of the peculiar state of the abdomen, and the increased sensibility of the body, are thought of sufficient interest to be inserted in your valuable Journal, I shall feel obliged, and remain, Sir, your very obedient servant,

HenRY Moon, M.R.C.S.

Lewes, May 12, 1841.

\section{COLICA PICTONUM.}

\section{To the Editor of THE LANCET.}

Sir:-The early doctrines at one time \$o warmly advocated, and even in some cases so clearly demonstrated, as to the pathology of this disease, are shown to be erroneous; firstly, by the comparatively short period in which a cure is now usually effected; and, secondly, by the examination of those cases which have terminated fatally from some other affection at the commencement of this disease, in which ulcerations of the intestines have never been discovered. It is nevertheless true, that this condition of the mucous membrane has really existed in those cases which have been brought forward as illustrations of this morbid state of the chylopoietic viscera giving rise to the disease; but it must at the same time be remembered, that there were cases in which the disease had existed some time before the result was fatal, and which may consequently be looked upon rather as the effect than the cause of the disease. From morbid pathology we can really derive but little assistance, and that too, if obtained from the source to which I have before referred, will, in all probability, lead us to incorrect conclusions : the question which now arises to be considered is, whether the disease is caused by spasm; or by loss of tone, depending upon some particular action on the nervous system, produced either by direct absorption of the poison, or the influence of some peculiar miasma, with which the warmer climate of the Indies is found at particular seasons of the year to be impregnated; and in which countries this sometimes occurs as an endemic, but, however, under a different name. With regard to the correctness of the spasmodic theorists, the facts adduced by them upon the post-r.ortem appearances, as to the existence of spasmodic contraction of certain portions of the intestinal canal, argue nothing; for these appearances are frequently met with in individuals who have died from external violence, and in whom the contents of the several cavities have been found perfectly normal. The therapeutic agents, likewise, brought forward in the treatment in the form of narcotics, are found of little avail, unless followed by the action of some stimulating purgative, and will consequently tend to prove the fallacy of this theory. In favour of the correctness of the disease depending upon paralysis of the muscular fibres of the 
intestine, are not only the most characteristic symptoms of the disease, whether produced by accidental absorption, or the direct administration of the poison, but also the therapeutic means I have adopted in arcordance with this theory (which consists in the application of a blister to the spine); counter-irritation is no sooner produced than the symptoms are alleviated, and the bowels act: in some cases I have subsequently administered a cathartic, and the patient is thus enabled to resume his employment in thirty or thirty-six hours. The frequent occurrence - of paralysis of the muscles of the extremitics supervening upon numerous or longcontinued attacks of the disease, and the individual not unfrequently dying with all the concomitant symptoms of apoplexy; thongh we are totally unable to discover any disease in the brain or spinal column to account for death, also tend to the same opinion. I remain, Sir, yours most obediently,

Whitehaven, May 1, 1841.

J. Dixon.

\section{REMARKABLE CASE OF FALSE CONCEPTION,}

ACCOMPANIED WITH OVARIAN DISEASE.

\section{To the Editor of The Lancet.}

Sir:-The accompanying ontlines of a case occurring in my practice may prove interesting to some of your readers, should you consider it worthy a place in your Journal. I am, Sir, your obedient servant,

43, Bishopsgate Within, JohN Grove. May $8,1841$.

Case of Mrs. A., twenty-five years of age, married at the age of seventeen, and now pregnant for the eighth time.

Having been engaged to attend her in her confuement, I was summoned to visit her on Sunday, the 21 st of March, at eleven, P.M., it being stated that she was in labour. On my arrival I found her lying on the bed, with a flushed face, violent action of the carotids, and a general turgidity of the ves. sels of the head; this appeared to be the result of immoderate fits of suppressed langhter (excited by wandering of the mind to scenes that had occurred in connection with her avocation); then followed apparently active labour-pains, which lasted but a short time, and were succeeded by coma; this, also, was of short duration; and the same train of symptoms were being repeated, when my patient, being of a plethoric habit, I took from the arm a suficient quantity of blood to aff-ct the pulse, which placed her comparatively in a much better condition, the head being much relieved. I then ordered some saline medicine, and being satisfied that labour was not at hand, left her, with an injunction to the attendant, that if any thing untoward should occur, to send immediately for me.

At seven o'clock on the following morning I was again sent for, and discovered that the only cause for this summons was the desire of the relatives that labour should be brought on; not agreeing with their view of the matter, an aperient only was ordered, and I left the patient tolerably well.

During the day Mrs. A. expressed a con. viction that she should go ber full time, nameiy, to the early part of April, for which time she had engaged me; I was also informed that the secretion of milk, which had been very abundant, so as literally to flow from the breasts, had ceased about a fort. night since, and that the breasts had become flaccid.

March 23. The medicine operated freely; says she intends to proceed with her business to-morrow. I discovered that on Stturday she received accidentally a blow on her side, which was, doubtless, the cause of the disturbance in her health.

On Sunday, April 4, at eleven, P.M., I was agrin called to Mrs. A., and found her sufferin the bowels had not been relieved, I ordered an enema, which being strongly objected to, a dose of castor-oil was administered. No examination allowed.

April 5, eight, A.M. The bowels relieved twice, the second time followed by extensive fooding, and a cessation of the pains; there was also slight hæmoptysis: puise 90 , soft; the conntenance good, and no flagging of the spirits. Ordered sulphuric acid and infusion of roses every five hours.

Nine, P.M. Much the same as in the moraing; flooding had not returned. Examina. tion, per raginam, proved the os uteri to be firmly and nidly contracted, and rather prominent. This was all that could be distinctly made out. To continue the medi. cine.

6. Much the same; hæmoptysis nearly gone, and no return of the flooding.

7. No material change, but a slight oozing of blood. An examioation was considered unuecessary by the patient, and firmly resisted, as it bad been also on the morning of the 5 th.

8. At four, A.Mr,, a messenger arrived, stating that Mrs. A. required my immediate attendance. I was speedily with her. She was quite insensible-in a state of syncope; yet liere was a character in the pulse which astonished me, but at the same time gave an opportumity of directing iny attention first to the parts engaged in parturition. I found a large mass, which had no connection with the woman, lying in the bed; the os uteri firmly contracted, and as rigid as on the former examination, not adnutting, as far as 1 could judge, of my finger-nail: no hæmorrhage. 'The mass was then removed 